\title{
Review Article \\ Evaluation of Implant Collar Surfaces for Marginal Bone Loss: A Systematic Review and Meta-Analysis
}

\author{
Roodabeh Koodaryan and Ali Hafezeqoran \\ Department of Prosthodontics, Faculty of Dentistry, University of Medical Sciences, Tabriz 5166614711, Iran \\ Correspondence should be addressed to Ali Hafezeqoran; hafezeqoran@gmail.com
}

Received 26 March 2016; Accepted 5 June 2016

Academic Editor: Gilberto Sammartino

Copyright (c) 2016 R. Koodaryan and A. Hafezeqoran. This is an open access article distributed under the Creative Commons Attribution License, which permits unrestricted use, distribution, and reproduction in any medium, provided the original work is properly cited.

\begin{abstract}
Background. It is important to understand the influence of different collar designs on peri-implant marginal bone loss, especially in the critical area. Objectives. The purpose of the present systematic review and meta-analysis was to compare dental implants with different collar surfaces, evaluating marginal bone loss and survival rates of implants. Methods. Eligibility criteria included clinical human studies, randomized controlled trials, and prospective and retrospective studies, which evaluated dental implants with different collar surface in the same study. Results. Twelve articles were included, with a total of 492 machined, 319 roughsurfaced, and 352 rough-surfaced microthreaded neck implants. There was less marginal bone loss at implants with rough-surfaced and rough-surfaced microthreaded neck than at machined-neck implants (difference in means: 0.321, 95\% CI: 0.149 to $0.493 ; p<$ 0.01). Conclusion. Rough and rough-surfaced microthreaded implants are considered a predictable treatment for preserving early marginal bone loss.
\end{abstract}

\section{Introduction}

The long-term clinical and aesthetic outcome of implantsupported restoration depends on preservation of both soft and hard tissues around implant [1-3]; thus the overall amount of crestal bone loss may influence the clinical success. Initial breakdown of peri-implant bone takes place in the most coronal portion of the bone-implant interface [1]. Bone resorption of 1.5 to $2 \mathrm{~mm}$ is observed during the first year of function and is generally considered a normal physiologic process. Successive annual bone loss of $0.2 \mathrm{~mm}$ occurs in subsequent years [4-6].

Many factors have been proposed to contribute to the marginal bone loss (MBL) around an implant. Factors such as unfavorable stress distribution, surgical trauma, implantabutment microgap, and bacterial infiltration result in apical migration of the biologic width; thus the bone is protected from further irritation [7-10]. Implant neck design and surface characterization have been associated with reduced marginal bone loss $[1,11,12]$; this has led to the development of implants with new collar configuration and topographic modification in order to improve the soft and hard tissue osseointegration. Up to date, there is no consensus in the literature relative to the effectiveness of these configurations and their influence on the MBL. Implants with a shorter polished smooth collar have proven to be more effective in decreasing MBL [13]. Likewise, implants with coronal retentive grooves may provide more stable peri-implant bone levels [14-16]. Although the amount of MBL after functional loading was not significant with regard to rough and microthreaded configuration, the polished collar showed the highest amount of crestal bone loss in any follow-up periods [15]. Unfortunately, the available data are not sufficient to sustain a conclusion with regard to the neck configurations.

The present systematic review and meta-analysis were conducted to evaluate the MBL around implants with different collar surfaces. The null hypotheses are as follows: (1) there are no differences in marginal bone loss in patients who received dental implants with different collar surface characterizations and (2) there are no differences among dental implants with different collar characterizations with regard to survival rates of implants. 


\section{Methods}

This systematic review adheres to the criteria of the PRISMA statement [17]. Electronic searches without time restrictions were performed in the PubMed, Embase, and The Cochrane Library databases for relevant publications until 15 July 2016. Search terms used in this study were dental implant, oral implant, neck, design, bone remodeling, and marginal bone loss connected with OR and AND.

Authors also manually searched the literature for relevant publications in British Journal of Oral and Maxillofacial Surgery, Clinical Implant Dentistry and Related Research, Clinical Oral Implants Research, European Journal of Oral Implantology, Implant Dentistry, International Journal of Oral and Maxillofacial Implants, International Journal of Oral and Maxillofacial Surgery, International Journal of Periodontics and Restorative Dentistry, International Journal of Prosthodontics, Journal of Clinical Periodontology, Journal of Dental Research, Journal of Dentistry, Journal of Oral Implantology, Journal of Craniofacial Surgery, Journal of Cranio-Maxillofacial Surgery, Journal of Maxillofacial and Oral Surgery, Journal of Oral and Maxillofacial Surgery, and Journal of Periodontology.

2.1. Eligibility Criteria. The studies were included if they met the following inclusion criteria: (1) randomized clinical trials (RCTs), (2) retrospective and prospective studies, (3) comparing different collar surfaces, (4) follow-up periods of longer than 1 year, and (5) published in English.

Exclusion criteria were (1) case reports, (2) computational studies, (3) animal studies, (4) in vitro studies, (5) studies that evaluated only one type of collar design, and (6) review papers.

Based on population, intervention, control, and outcome (PICO) criteria the focused question was "what is the best implant collar configuration for preservation of MBL?" and the population was the patients undergoing implantprosthetic rehabilitation with machined, rough, or roughsurfaced microthreaded neck configurations. The two outcomes evaluated were the survival rates and MBL of implants.

2.2. Study Selection. The titles were screened independently by the two reviewers. Abstracts of studies were inspected and those appearing to meet the inclusion were retrieved. Also, all reference lists of the selected studies and relevant reviews were scanned to identify articles that have been missed in database searches. Disagreements were settled by discussion between the authors until a consensus was achieved.

2.3. Quality Assessment. All studies were assessed for quality depending on whether they met all the quality criteria or if one or more criteria were partially met or not met using the Jadad scoring system [18] which ranges from 0 to 5 . Studies with a Jadad score of 3 or higher were considered of high quality.

2.4. Summary Measures. The meta-analysis was based on the Mantel-Haenszel and inverse variance methods. Survival rates of implants were the dichotomous outcome measure expressed in risk ratio (RR) and marginal bone loss and

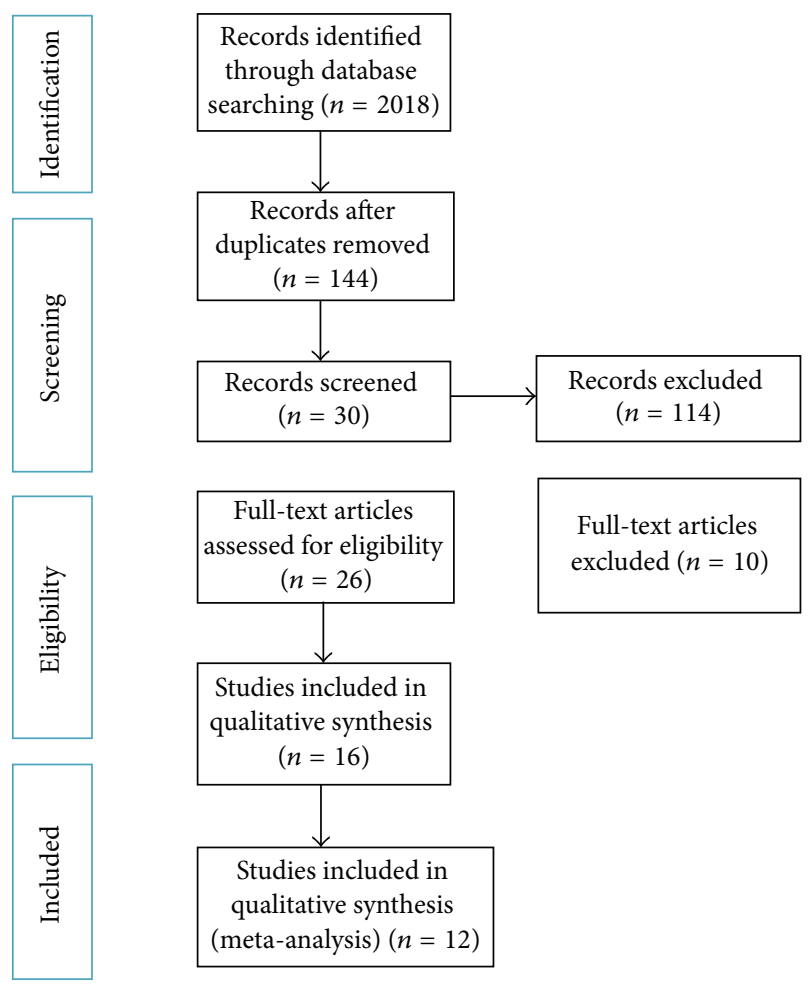

FIGURE 1: Diagram of the search strategy.

the continuous outcome measure expressed in mean difference (MD), both with a $95 \%$ confidence interval (CI). The RR and $\mathrm{MD}$ values were considered significant when $p<0.05$. The data were analyzed using comprehensive meta-analysis software (CMA 2.0) (BioStat Inc., Englewood, New Jersey, USA).

\section{Results}

3.1. Literature Search. The search in the databases retrieved 2018 references, including 1778 from PubMed/MEDLINE, 229 from Embase, and 11 from The Cochrane Library. The identification and removal of duplicate references and application of the inclusion/exclusion criteria yielded 19 publications (14 cohorts, 2 retrospective studies, and 3 randomized controlled trials (RCT)) for further eligibility assessment (Figure 1). After qualitative assessment of the selected studies and reading the full texts of these publications, 12 studies $[3,15,19-29]$ remained for inclusion in the quantitative metaanalysis (Tables 1 and 2).

3.2. Description of the Studies. A total of 12 studies were included in this quantitative meta-analysis which were published from 1998 to 2015. A total of 1163 implants and 930 patients were evaluated, and of these, 492 implants were machined, 319 rough-surfaced, and 352 rough-surfaced microthreaded. The follow-up periods were between 1 and 10 years. Eight of the selected studies [3, 15, 21-25, 27] evaluated the survival rates in relation to the type of collar surface characterization. Radiographic evaluation of MBL was performed 


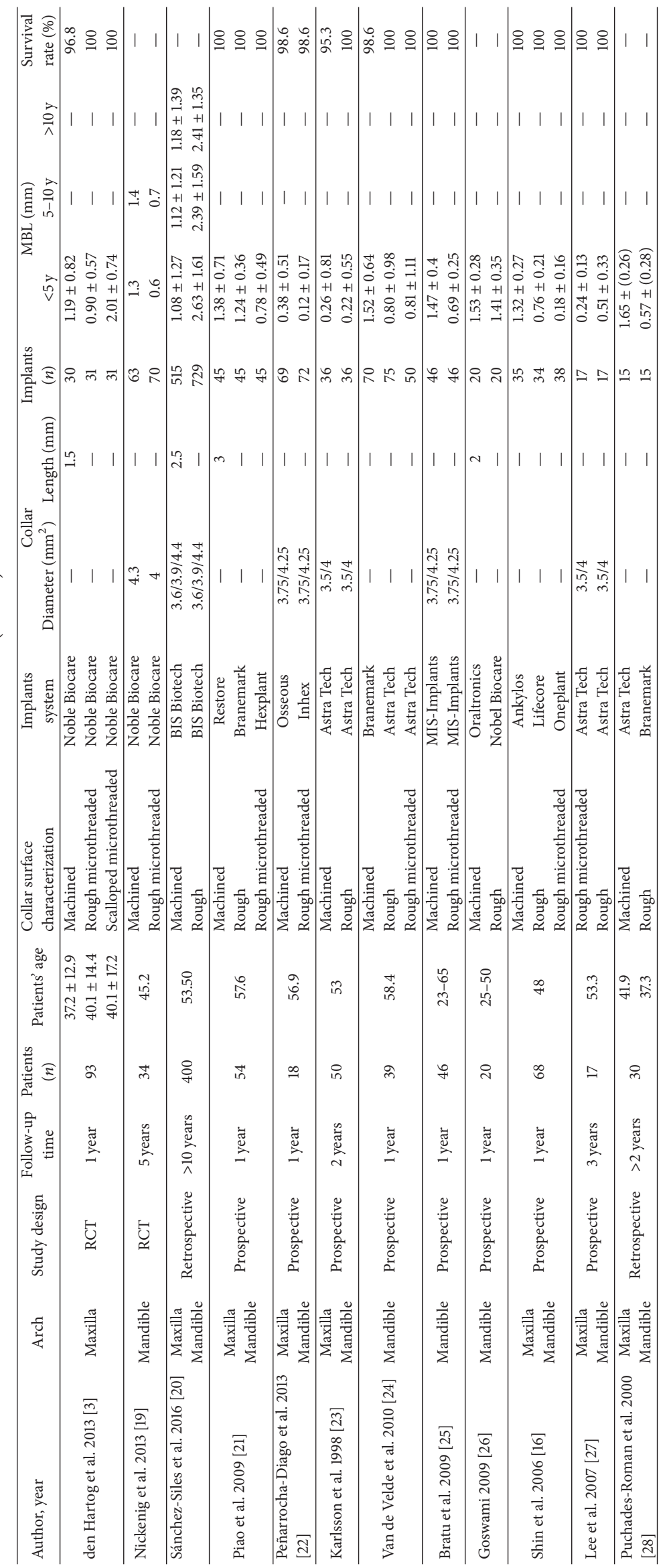




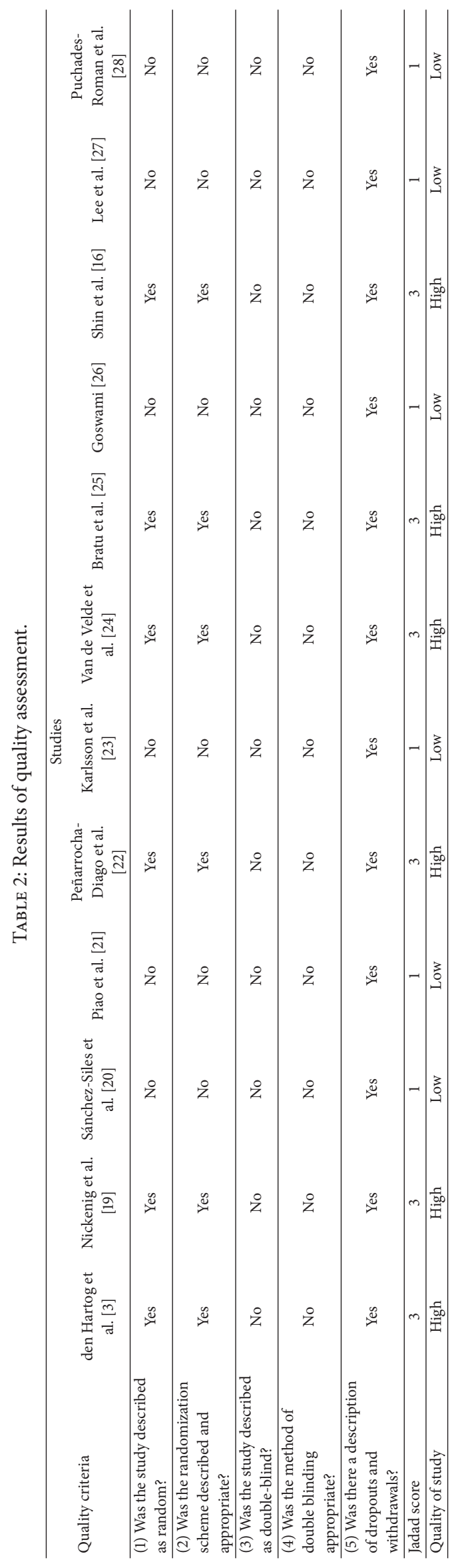


by means of periapical radiographs in 9 studies $[3,15,20-$ $24,27,28]$, panoramic radiographs in two studies $[19,25]$, and maxillofacial CT in one study [26]. Rough and machined collars were considered in 7 studies $[15,20,21,23,24,26$, 28]; while machined and microthreaded neck implants were installed in seven studies $[3,15,19,21,22,24,25]$. Only four studies compared microthreaded collar with roughened neck surfaces [15, 21, 24, 27].

The RCT study by den Hartog et al. [3] found a significantly greater marginal bone loss around smooth collars (1.19 $\pm 0.82 \mathrm{~mm})$ compared with rough-surfaced neck implants $(0.90 \pm 0.57 \mathrm{~mm})$ after 18 months of implant placement. One smooth-necked implant was lost 5 months after implant placement; thus, the survival rate was $96.8 \%$ at 18 months after implant placement compared with $100 \%$ of rough-surfaced collar. Nickenig et al. [19] determined marginal bone level changes around 70 rough-surfaced microthreaded and 63 machined-neck implants at six time points of implant placement, with a median follow-up time of 5.2 years. The two implant types revealed significant marginal bone level changes. The machined-neck implants were associated with a mean bone loss of $0.8 \mathrm{~mm}$ after six months of loading, $1.1 \mathrm{~mm}$ at two years' follow-up, $1.3 \mathrm{~mm}$ at three years' follow-up, and $1.4 \mathrm{~mm}$ at five years' follow-up, while the rough-surfaced microthreaded implants showed a mean crestal bone loss of 0.4 after six months of loading, $0.5 \mathrm{~mm}$ at two years' follow-up, $0.6 \mathrm{~mm}$ at three years' follow-up, and $0.7 \mathrm{~mm}$ at five years' follow-up. A 10-year retrospective study of 400 patients receiving 1244 implants by SánchezSiles and colleagues [20] assessed radiographic bone loss around implants with or without smooth collar designs. It was observed that smooth-necked implants had significantly lower amounts of marginal bone loss $(1.18 \pm 1.39 \mathrm{~mm})$ compared with rough-surfaced implants $(2.41 \pm 1.35 \mathrm{~mm})$ after 10 years of function $(p<0.001)$. Piao et al. [21] compared three different implant systems with a machined, rough, and rough-surfaced microthreaded neck in relation to marginal bone loss and detected significant differences $(p<0.0001)$. Implants with the rough-surfaced microthreaded collar surfaces had the least amount of bone loss $(0.42 \pm 0.27 \mathrm{~mm})$ while the machined surface had the greatest amount $(0.89 \pm$ $0.41 \mathrm{~mm}$ ) after one year of loading. In a RCT study by Peñarrocha-Diago et al. [22] MBL was evaluated around 69 dental implants with machined surface collar, external connection, and without platform switching and 72 implants with rough-surfaced microthreaded collar, internal connection, and with platform switching. MBL changes for machined and microthreaded implants were $0.38 \pm 0.51 \mathrm{~mm}$ and $0.12 \pm 0.17 \mathrm{~mm}$, respectively, 12 months after loading $(p=$ 0.047). $34 \%$ of rough-surfaced microthreaded and $56 \%$ of the machined-neck implants had $3.75 \mathrm{~mm}$ diameter and the rest were $4.25 \mathrm{~mm}$ in diameter. A positive correlation was found between an increased implant diameter and the amount of bone loss $(p=0.034)$; however, no significant differences were observed in MBL around different neck configurations according to implant diameters. Moreover, no significant differences were found in bone loss changes in terms of patient's age and gender in implant groups. Subjects were comprehensively treated with bar over dentures and fixed prostheses.
The greatest marginal bone loss was attributed to machinedneck configuration in combination with bar overdentures ( $p=0.034$ ). They reported $98.6 \%$ survival and $97.1 \%$ success rate for machined-neck and $98.6 \%$ survival and $97.2 \%$ success rate for microthreaded implants after 12 months of loading.

Karlsson et al. [23] reported the cumulative survival rate of $97.7 \%$ for Astra Tech implants with no significant difference between machined (95.3\%) and TiOblast-surfaced collars $(100 \%)(p=0.24)$. Moreover, the amount of bone loss did not differ significantly between the two groups, 2 years after prosthesis placement $(p>0.3)$. Another study by Van de Velde and colleagues [24] focused on implants with machined, rough, and rough microthreaded neck and followed up to one year after loading. The mean MBL was $1.52 \pm 0.66 \mathrm{~mm}$, $0.79 \pm 0.79 \mathrm{~mm}$, and $0.70 \pm 1.01 \mathrm{~mm}$ for implants with machined, rough, and rough microthreaded neck. A significant difference in MBL existed between machined and rough neck $(p=0.23)$ and between machined and rough-surfaced microthreaded neck implants $(p=0.046)$; however, the amount of bone loss around implants with rough collars was not statistically different compared with rough microthreaded neck implants $(p=0.7)$. They reported 1-year survival rate of $98.6 \%$ for machined, $100 \%$ for rough, and $100 \%$ for rough-surfaced microthreaded neck implants.

Bratu et al. [25] found that the machined-neck implants, which showed premature exposure, exhibited significantly greater amounts of MBL compared to those with intact soft tissue coverage $(p<0.05)$. This event was not statistically significant for rough neck implants. However, it is noteworthy to mention that the low occurrence of dehiscence in both collar configurations (eight in machined and four in microthreaded neck implants) prevents the drawing of definite conclusions.

The prospective study by Shin et al. [16] compared marginal bone loss around implants with machined, rough, and rough microthreaded neck designs at 1 year after loading. Rough-surfaced microthreaded neck showed the least $(0.18 \pm$ 0.27) amount of crestal bone loss. The greatest amount of MBL was observed around machined collars which was statistically significant at every follow-up period. Neither rough collar nor rough microthreaded neck implants showed significant bone loss at 3 months after implant placement $(p<$ 0.05).

3.3. Interinvestigator Agreement. The Kappa interinvestigator agreement was 0.87 for studies extracted from PubMed/ MEDLINE, 0.86 for Embase, and 0.91 for The Cochrane Library and showed a high level of agreement.

3.4. Marginal Bone Loss. 12 studies assessed the mean marginal bone changes $(\mathrm{mm})$ around the implants in different follow-up periods. The range of marginal bone loss in machined-neck groups, rough-surfaced collar, and roughsurfaced microthreaded neck groups was 0.26 to $1.6 \mathrm{~mm}, 0.22$ to $2.63 \mathrm{~mm}$, and 0.14 to 0.81 , respectively. Implants with rough collars showed significantly greater $\mathrm{MBL}$ than machinedneck implants ( $p<0.01$; MD: 0.321 ; and 95\% CI: 0.149 to 0.493). In addition, rough-surfaced microthreaded implants had significantly higher MBL than machined ( $p<0.01$; MD: 1.098 ; $95 \%$ CI: 0.934 to 1.263 ) and rough-surfaced neck 


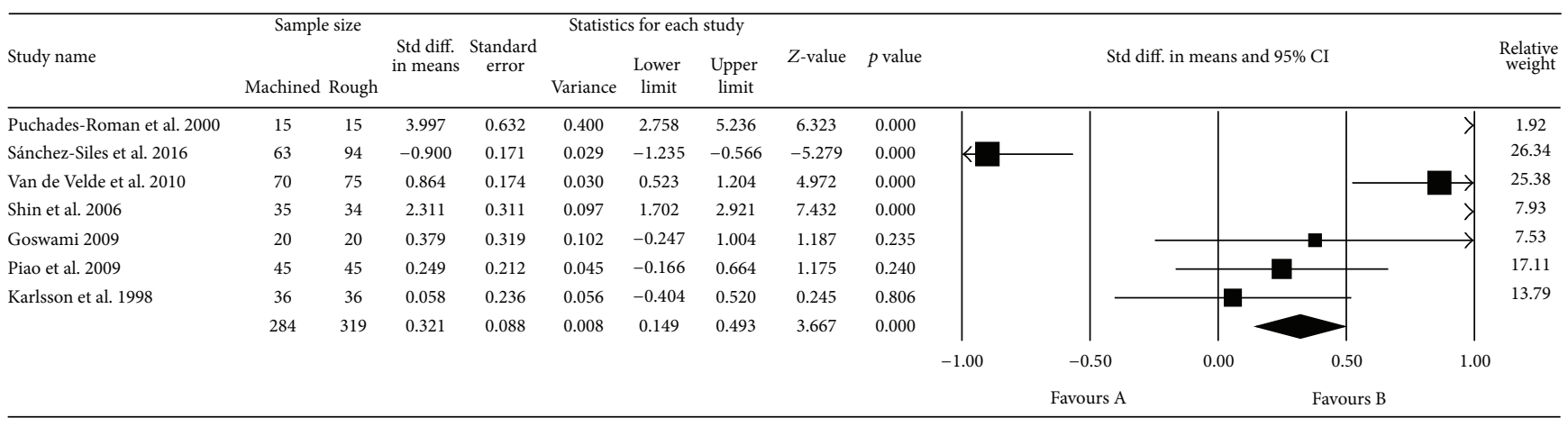

(a)

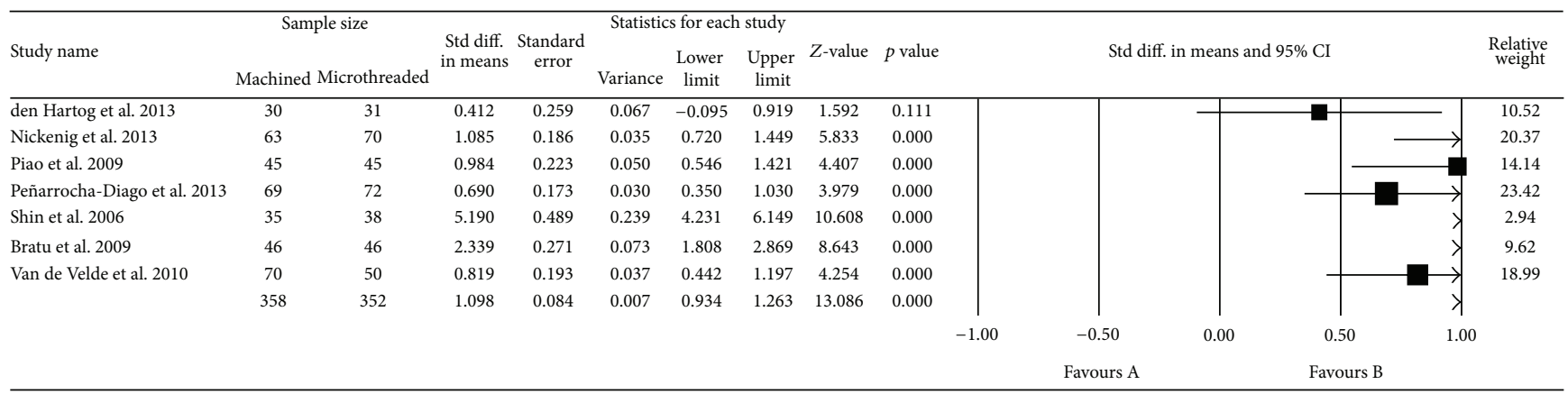

(b)

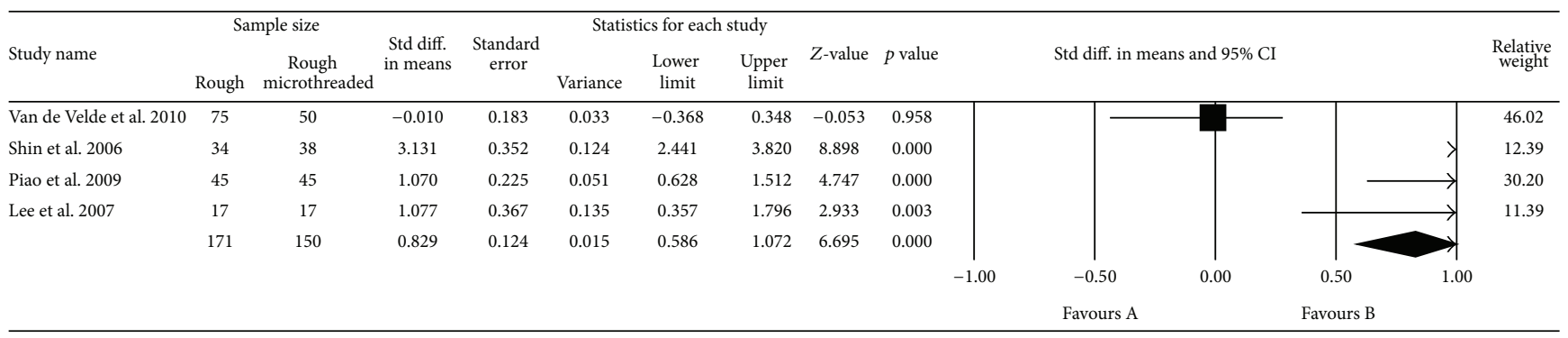

(c)

Figure 2: Forest plot for the event "marginal bone loss" in the comparison between machined and rough-surfaced neck implants (a), machined and rough-surfaced microthreaded neck implants (b), and rough and rough-surfaced microthreaded neck implants (c).

implants $(p<0.01$; MD: $0.829 ; 95 \% \mathrm{CI}: 0.586$ to 1.072$)$ (Figure 2).

3.5. Survival Rates of Implants. The assessed studies $[3,15,21-$ $25,27]$ showed that 7 out of 420 implants failed $(1.66 \%)$, comprising 5 machined-neck implants $(1.11 \%)$ and 2 roughsurfaced microthreaded implants $(0.47 \%)$ (Figure 3 ). All accepted studies showed more favorable survival rate in rough-surfaced implants than those with machined implants, but none showed this difference to be statistically significant. Quantitative analysis revealed that there was no statistically significant difference due to the implant neck surface characterization ( $p=0.417$; RR: 1.810; 95\% CI: 0.431-7.59).

\section{Discussion}

The present systematic review showed that insertion of implants with rough and rough-surfaced microthreaded neck implants influenced the rate of bone loss and favored lesser MBL compared to machined-neck implants. Thus the null hypothesis of the study that there would be no difference between different collar surfaces of the implant with regard to marginal bone loss was rejected.

All implants have some degrees of bone loss following implant installation and loading. An early implant bone loss of $1.5 \mathrm{~mm}$ occurs during the healing phase and the first year in function at the crestal area of implants, followed by an annual bone loss of $0.2 \mathrm{~mm}$ thereafter $[1,4,5]$. Until now, the basic mechanisms underlying early peri-implant marginal bone loss are not clarified [12, 13, 20, 29, 30]. Surgical trauma, the establishment of biologic width, lack of passive fit of the superstructures, the presence of a microgap at implantabutment interface, occlusal overload, and implant neck design are among the possible etiologic factors [2, 8, 9, 3136]. 


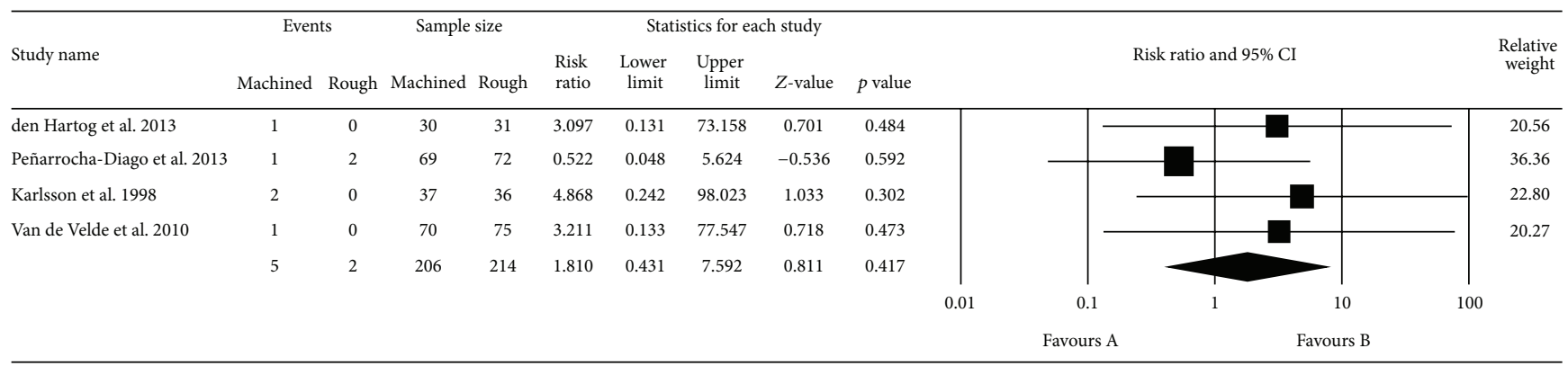

FIGURE 3: Forest plot for the event "survival rate" in the comparison between machined and rough-surfaced neck implants.

Different implant neck designs have been proposed in order to stabilize the bone-implant contact $[19,20,26,29,37]$. The smooth neck implants result in reduced plaque accumulation and thus presumably prevent peri-implantitis $[15$, 16, 22]. However, FEA investigations revealed high stress concentrations in the area of crestal bone around the polished neck of dental implants [38,39]. Thus MBL might be partially attributed to the lack of favorable stress distributions at the coronal portion of the implants [14].

In vivo experiments revealed that the rough-surface dental implants dramatically enhanced bone-implant interface and lowered the rate of bone loss compared with smooth surfaces [40, 41]. Moreover, the presence of microthread at the neck area might provide an increased interlocking of the implant and the marginal bone, thus reducing the MBL $[14$, 15, 42]. Hansson [14] found that implant surface roughness at the implant neck area leads to an increased interfacial shear strength and is effective in counteracting MBL. This result is supported by some recent clinical studies while other investigations found no significant differences in MBL $[21,23$, $43,44]$. It is noteworthy to mention that the current systematic review included only those studies comparing rough or rough-surfaced microthreaded implants with machinedneck implants in order to perform a direct comparison.

The result for selected studies revealed that marginal bone changes were decreased around rough-surfaced microthreaded neck implants compared with polished and roughsurfaced neck implants. However only 2 of the 12 studies included in the meta-analysis were RCTs with greater clinical reliability. Only three studies followed up the cases more than 5 years and the rest were with 1-year follow-up. The 10year retrospective study by Sánchez-Siles et al. [20] evaluated a total of 1244 implants with and without smooth neck and concluded that $2.5 \mathrm{~mm}$ smooth-necked implants suffered less bone loss and peri-implantitis at any follow-up time interval. Conversely, Chappuis et al. [29] reported a median of lower bone changes around rough implant necks after followup periods of 5 to 9 years. Other studies evaluated bone loss around rough necks with short follow-up periods and achieved good results $[15,19,22,24]$.

An important issue to consider is the presence of several confounding factors in the studies. It is known that titanium surface topography and chemistry affect the osseointegration [45-47]. Moderate Surface roughness improves the bone-implant contact which may have favored improved osseointegration and preservation of the marginal bone level [46]. The majority of the evaluated studies did not provide information about surface topography characterizations of implants. Implant-abutment connection is also an important factor in crestal bone level [22, 48-50]. Mostly, comparative studies were conducted among heterogeneous groups, comparing different implant neck designs and implantabutment connections with or without platform switching with regard to marginal bone loss $[15,19,21,22,24-26$, 28]. Peñarrocha-Diago et al. [22] compared two groups of implants; machined-neck, externally connected, and platform matched Osseous ${ }^{\circledR}$ implants were compared with rough microthreaded, internally connected, and platform switched Inhex ${ }^{\circledR}$ implants. Greater marginal bone loss was observed in the case of Osseous implants with no platform switching. However, the possible effect of platform switching or implantabutment connection upon marginal bone loss was not considered.

The studied population was patients with a wide range of ages. Age is an important factor that can affect bone formation and resorption. The relationship between advancing age in adults and patterns of cortical bone maintenance has been extensively documented $[51,52]$. In a study by Negri et al. [53], marginal bone loss was progressively increased with age and the greatest amount of marginal bone loss was observed in women of 50 to 60 years of age.

Regarding the type of prostheses design, details of the treatment were not frequently present. Almost all of the studies rehabilitated the patients with fixed prostheses and only one was implant supported over denture. However, the effect of splinting was not defined. Splinting dissipates the loads between implants and reduces the stress and influences the results.

Data on peri-implant health were frequently not present in studies. This cannot be excluded as risk factors for peri-implant bone disease. Only Sánchez-Siles et al. [20] reported that 120 implants developed peri-implantitis and the incidence of peri-implantitis for roughened neck implants (2.92\%) was much lower than smooth necks (14.41\%).

There is another arguably more insidious source of confounding, however, and that is the method of assessment of MBL. Varying the X-ray exposure parameters of the different manufacturers and measurement tools may account 
for sources of bias. In the evaluated studies, dental intraoral, panoramic radiographs and maxillofacial CT scans provided an estimate of changes over follow-up intervals. Standardized digital intraoral radiographs were used for radiographic assessment in 10 studies. Likewise, different implant systems and neck designs were included; thus MBL could not be assessed in relation to a standard reference point. Investigating the marginal bone level changes from baseline at each follow-up time point has been suggested. However, only 7 studies reported the radiographic marginal bone changes from baseline.

Considering these limitations, the findings of the current study should be interpreted cautiously. Several other confounding factors influence the survival of implants and thus MBL is not only affected with collar configuration. Grafting, insertion of implants in freshly extracted teeth sockets, various healing periods, occlusion of the opposite arch, angulations of implants, and bone type are among other confounding variables. Prediction of these factors is only applicable when other metaregressions of two other process are performed. Study population has several confounding factors simultaneously and in this regard is considered heterogenic; hence it seems impossible to isolate risk factors as a separate study. Thus, coexistence of other risk factors in population of the study makes the evaluation of one particular risk factor impossible and the lack of control over these factors lowers the potential of definitive result extraction.

\section{Conclusion}

The result of the present systematic review revealed that marginal bone changes around rough-surfaced microthreaded neck implants were significantly lower than polished and rough-surfaced neck implants. However, considering the limitations of the current study, the results should be interpreted cautiously.

\section{Competing Interests}

The authors declare that they have no competing interests.

\section{References}

[1] T.-J. Oh, J. Yoon, C. E. Misch, and H.-L. Wang, “The causes of early implant bone loss: myth or science?” Journal of Periodontology, vol. 73, no. 3, pp. 322-333, 2002.

[2] D. P. Tarnow, S. C. Cho, and S. S. Wallace, "The effect of interimplant distance on the height of inter-implant bone crest," Journal of Periodontology, vol. 71, no. 4, pp. 546-549, 2000.

[3] L. den Hartog, G. M. Raghoebar, J. J. H. Slater, K. Stellingsma, A. Vissink, and H. J. A. Meijer, "Single-tooth implants with different neck designs: a randomized clinical trial evaluating the aesthetic outcome," Clinical Implant Dentistry and Related Research, vol. 15, no. 3, pp. 311-321, 2013.

[4] D. E. Smith and G. A. Zarb, "Criteria for success of osseointegrated endosseous implants," The Journal of Prosthetic Dentistry, vol. 62 , no. 5 , pp. 567-572, 1989.

[5] D. Buser, H. P. Weber, and N. P. Lang, "Tissue integration of non-submerged implants. 1-year results of a prospective study with 100 ITI hollow-cylinder and hollow-screw implants," Clinical Oral Implants Research, vol. 1, no. 1, pp. 33-40, 1990.

[6] H. P. Weber, D. Buser, J. P. Fiorellini, and R. C. Williams, "Radiographic evaluation of crestal bone levels adjacent to nonsubmerged titanium implants," Clinical oral Implants Research, vol. 3, no. 4, pp. 181-188, 1992.

[7] H. E. K. Bae, M.-K. Chung, I.-H. Cha, and D.-H. Han, "Marginal tissue response to different implant neck design," The Journal of Korean Academy of Prosthodontics, vol. 46, no. 6, pp. 602-609, 2008.

[8] G. M. Baffone, D. Botticelli, F. P. Pereira, G. Favero, M. Schweikert, and N. P. Lang, "Influence of buccal bony crest width on marginal dimensions of peri-implant hard and soft tissues after implant installation. An experimental study in dogs," Clinical Oral Implants Research, vol. 24, no. 3, pp. 250-254, 2013.

[9] F. Bengazi, N. P. Lang, M. Caroprese, J. Urbizo Velez, V. Favero, and D. Botticelli, "Dimensional changes in soft tissues around dental implants following free gingival grafting: an experimental study in dogs," Clinical Oral Implants Research, vol. 26, no. 2, pp. 176-182, 2015.

[10] N. Broggini, L. M. McManus, J. S. Hermann et al., "Persistent acute inflammation at the implant-abutment interface," Journal of Dental Research, vol. 82, no. 3, pp. 232-237, 2003.

[11] X. Rodríguez-Ciurana, X. Vela-Nebot, M. Segala-Torres et al., "The effect of interimplant distance on the height of the interimplant bone crest when using platform-switched implants," International Journal of Periodontics and Restorative Dentistry, vol. 29, no. 2, pp. 141-151, 2009.

[12] J. L. Calvo-Guirado, A. J. Ortiz-Ruiz, B. Negri, L. López-Marí, C. Rodriguez-Barba, and F. Schlottig, "Histological and histomorphometric evaluation of immediate implant placement on a dog model with a new implant surface treatment," Clinical Oral Implants Research, vol. 21, no. 3, pp. 308-315, 2010.

[13] J. L. Calvo-Guirado, P. J. López-López, J. E. Maté Sánchez de Val, J. Mareque-Bueno, R. A. Delgado-Ruiz, and G. E. Romanos, "Influence of collar design on peri-implant tissue healing around immediate implants: a pilot study in Foxhound dogs," Clinical Oral Implants Research, vol. 26, no. 7, pp. 851-857, 2015.

[14] S. Hansson, "The implant neck: smooth or provided with retention elements. A biomechanical approach," Clinical Oral Implants Research, vol. 10, no. 5, pp. 394-405, 1999.

[15] S.-Y. Shin and D.-H. Han, "Influence of a microgrooved collar design on soft and hard tissue healing of immediate implantation in fresh extraction sites in dogs," Clinical Oral Implants Research, vol. 21, no. 8, pp. 804-814, 2010.

[16] Y.-K. Shin, C.-H. Han, S.-J. Heo, S. Kim, and H.-J. Chun, "Radiographic evaluation of marginal bone level around implants with different neck designs after 1 year," International Journal of Oral and Maxillofacial Implants, vol. 21, no. 5, pp. 789794, 2006.

[17] D. Moher, A. Liberati, J. Tetzlaff, D. G. Altman, and P. Grp, "Preferred reporting items for systematic reviews and metaanalyses: the PRISMA statement (reprinted from annals of internal medicine)," Physical Therapy, vol. 89, no. 9, pp. 873-880, 2009.

[18] A. R. Jadad, R. A. Moore, D. Carroll et al., "Assessing the quality of reports of randomized clinical trials: is blinding necessary?" Controlled Clinical Trials, vol. 17, no. 1, pp. 1-12, 1996.

[19] H.-J. Nickenig, M. Wichmann, A. Happe, J. E. Zöller, and S. Eitner, "A 5-year prospective radiographic evaluation of marginal bone levels adjacent to parallel-screw cylinder machinedneck implants and rough-surfaced microthreaded implants 
using digitized panoramic radiographs," Journal of CranioMaxillofacial Surgery, vol. 41, no. 7, pp. 564-568, 2013.

[20] M. Sánchez-Siles, D. Muñoz-Cámara, N. Salazar-Sánchez, J. F. Ballester-Ferrandis, and F. Camacho-Alonso, "Incidence of peri-implantitis and oral quality of life in patients rehabilitated with implants with different neck designs: a 10-year retrospective study," Journal of Cranio-Maxillofacial Surgery, vol. 43, no. 10, pp. 2168-2174, 2016.

[21] C. M. Piao, J. E. Lee, J. Y. Koak et al., "Marginal bone loss around three different implant systems: radiographic evaluation after 1 year," Journal of Oral Rehabilitation, vol. 36, no. 10, pp. 748-754, 2009.

[22] M. A. Peñarrocha-Diago, A. J. Flichy-Fernández, R. AlonsoGonzález, D. Peñarrocha-Oltra, J. Balaguer-Martínez, and M. Peñarrocha-Diago, "Influence of implant neck design and implant-abutment connection type on peri-implant health. Radiological study," Clinical Oral Implants Research, vol. 24, no. 11, pp. 1192-1200, 2013.

[23] U. Karlsson, K. Gotfredsen, and C. Olsson, "A 2-year report on maxillary and mandibular fixed partial dentures supported by Astra Tech dental implants: a comparison of 2 implants with different surface textures," Clinical Oral Implants Research, vol. 9, no. 4, pp. 235-242, 1998.

[24] T. Van de Velde, B. Collaert, L. Sennerby, and H. De Bruyn, "Effect of implant design on preservation of marginal bone in the mandible," Clinical Implant Dentistry and Related Research, vol. 12, no. 2, pp. 134-141, 2010.

[25] E. A. Bratu, M. Tandlich, and L. Shapira, "A rough surface implant neck with microthreads reduces the amount of marginal bone loss: a prospective clinical study," Clinical Oral Implants Research, vol. 20, no. 8, pp. 827-832, 2009.

[26] M. M. Goswami, "Comparison of crestal bone loss along two implant crest module designs," Medical Journal Armed Forces India, vol. 65, no. 4, pp. 319-322, 2009.

[27] D.-W. Lee, Y.-S. Choi, K.-H. Park, C.-S. Kim, and I.-S. Moon, "Effect of microthread on the maintenance of marginal bone level: a 3-year prospective study," Clinical Oral Implants Research, vol. 18, no. 4, pp. 465-470, 2007.

[28] L. Puchades-Roman, R. M. Palmer, P. J. Palmer, L. C. Howe, M. Ide, and R. F. Wilson, "A clinical, radiographic, and microbiologic comparison of Astra Tech and Brånemark single tooth implants," Clinical Implant Dentistry and Related Research, vol. 2, no. 2, pp. 78-84, 2000.

[29] V. Chappuis, M. M. Bornstein, D. Buser, and U. Belser, "Influence of implant neck design on facial bone crest dimensions in the esthetic zone analyzed by cone beam CT: a comparative study with a 5-to-9-year follow-up," Clinical Oral Implants Research, 2015.

[30] M. Esposito, Y. Ardebili, and H. V. Worthington, "Interventions for replacing missing teeth: different types of dental implants," The Cochrane Database of Systematic Reviews, no. 7, Article ID CD003815, 2014.

[31] M. Quirynen, I. Naert, and D. Van Steenberghe, "Fixture design and overload influence marginal bone loss and future success in the Brånemark ${ }^{\circledR}$ system," Clinical Oral Implants Research, vol. 3, no. 3, pp. 104-111, 1992.

[32] E. Kitamura, R. Stegaroiu, S. Nomura, and O. Miyakawa, "Influence of marginal bone resorption on stress around an implanta three-dimensional finite element analysis," Journal of Oral Rehabilitation, vol. 32, no. 4, pp. 279-286, 2005.

[33] F. Isidor, "Influence of forces on peri-implant bone," Clinical Oral Implants Research, vol. 17, supplement 2, pp. 8-18, 2006.
[34] M. Karl, W. Winter, T. D. Taylor, and S. M. Heckmann, "In vitro study on passive fit in implant-supported 5-unit fixed partial dentures," International Journal of Oral and Maxillofacial Implants, vol. 19, no. 1, pp. 30-37, 2004.

[35] J. S. Hermann, D. L. Cochran, P. V. Nummikoski, and D. Buser, "Crestal bone changes around titanium implants. A radiographic evaluation of unloaded nonsubmerged and submerged implants in the canine mandible," Journal of Periodontology, vol. 68, no. 11, pp. 1117-1130, 1997.

[36] A. Piattelli, G. Vrespa, G. Petrone, G. Iezzi, S. Annibali, and A. Scarano, "Role of the microgap between implant and abutment: a retrospective histologic evaluation in monkeys," Journal of Periodontology, vol. 74, no. 3, pp. 346-352, 2003.

[37] J. L. Calvo-Guirado, P. J. López-López, C. Pérez-Albacete Martínez et al., "Peri-implant bone loss clinical and radiographic evaluation around rough neck and microthread implants: a 5-year study," Clinical Oral Implants Research, 2016.

[38] R. Sadrimanesh, H. Siadat, P. Sadr-Eshkevari, A. Monzavi, P. Maurer, and A. Rashad, "Alveolar bone stress around implants with different abutment angulation: an FE-Analysis of anterior maxilla," Implant Dentistry, vol. 21, no. 3, pp. 196-201, 2012.

[39] L. Pierrisnard, F. Renouard, P. Renault, and M. Barquins, "Influence of implant length and bicortical anchorage on implant stress distribution," Clinical Implant Dentistry and Related Research, vol. 5, no. 4, pp. 254-262, 2003.

[40] N. Sato, T. Kuwana, M. Yamamoto et al., "Bone response to immediate loading through titanium implants with different surface roughness in rats," Odontology, vol. 102, no. 2, pp. 249258, 2014.

[41] A. Wennerberg, A. Ektessabi, T. Albrektsson, C. Johansson, and B. Andersson, "A 1-year follow-up of implants of differing surface roughness placed in rabbit bone," The International Journal of Oral \& Maxillofacial Implants, vol. 12, no. 4, pp. 486494, 1997.

[42] Y.-I. Kang, D.-W. Lee, K.-H. Park, and I.-S. Moon, "Effect of thread size on the implant neck area: preliminary results at 1 year of function," Clinical Oral Implants Research, vol. 23, no. 10, pp. 1147-1151, 2012.

[43] M. Hallman, A. Mordenfeld, and T. Strandkvist, "A retrospective 5-year follow-up study of two different titanium implant surfaces used after interpositional bone grafting for reconstruction of the atrophic edentulous maxilla," Clinical Implant Dentistry and Related Research, vol. 7, no. 3, pp. 121-126, 2005.

[44] P. Åstrand, B. Engquist, S. Dahlgren, K. Gröndahl, E. Engquist, and H. Feldmann, "Astra Tech and Brånemark system implants: a 5-year prospective study of marginal bone reactions," Clinical Oral Implants Research, vol. 15, no. 4, pp. 413-420, 2004.

[45] N. Sykaras, A. M. Iacopino, V. A. Marker, R. G. Triplett, and R. D. Woody, "Implant materials, designs, and surface topographies: their effect on osseointegration. A literature review," International Journal of Oral and Maxillofacial Implants, vol. 15, no. 5, pp. 675-690, 2000.

[46] A. Wennerberg and T. Albrektsson, "Effects of titanium surface topography on bone integration: a systematic review," Clinical Oral Implants Research, vol. 20, supplement 4, pp. 172-184, 2009.

[47] L. Le Guéhennec, A. Soueidan, P. Layrolle, and Y. Amouriq, "Surface treatments of titanium dental implants for rapid osseointegration," Dental Materials, vol. 23, no. 7, pp. 844-854, 2007. 
[48] F. Schwarz, A. Hegewald, and J. Becker, "Impact of implantabutment connection and positioning of the machined collar/microgap on crestal bone level changes: a systematic review," Clinical Oral Implants Research, vol. 25, no. 4, pp. 417-425, 2014.

[49] S. J. Caram, G. Huynh-Ba, J. D. Schoolfield, A. A. Jones, D. L. Cochran, and U. C. Belser, "Biologic width around different implant-abutment interface configurations. A radiographic evaluation of the effect of horizontal offset and concave abutment profile in the canine mandible," The International Journal of Oral \& Maxillofacial Implants, vol. 29, no. 5, pp. 1114-1122, 2014.

[50] P. van Eekeren, A. Tahmaseb, and D. Wismeijer, "Crestal bone changes around implants with implant-abutment connections at epicrestal level or above: systematic review and metaanalysis," The International Journal of Oral \& Maxillofacial Implants, vol. 31, no. 1, pp. 119-124, 2016.

[51] P. Beauchesne and S. C. Agarwal, "Age-related cortical bone maintenance and loss in an imperial roman population," International Journal of Osteoarchaeology, vol. 24, no. 1, pp. 15-30, 2014.

[52] H. Chen, X. Zhou, H. Fujita, M. Onozuka, and K.-Y. Kubo, "Agerelated changes in trabecular and cortical bone microstructure," International Journal of Endocrinology, vol. 2013, Article ID 213234, 9 pages, 2013.

[53] M. Negri, C. Galli, A. Smerieri et al., "The effect of age, gender, and insertion site on marginal bone loss around endosseous implants: results from a 3-year trial with premium implant system," BioMed Research International, vol. 2014, Article ID 369051, 7 pages, 2014. 

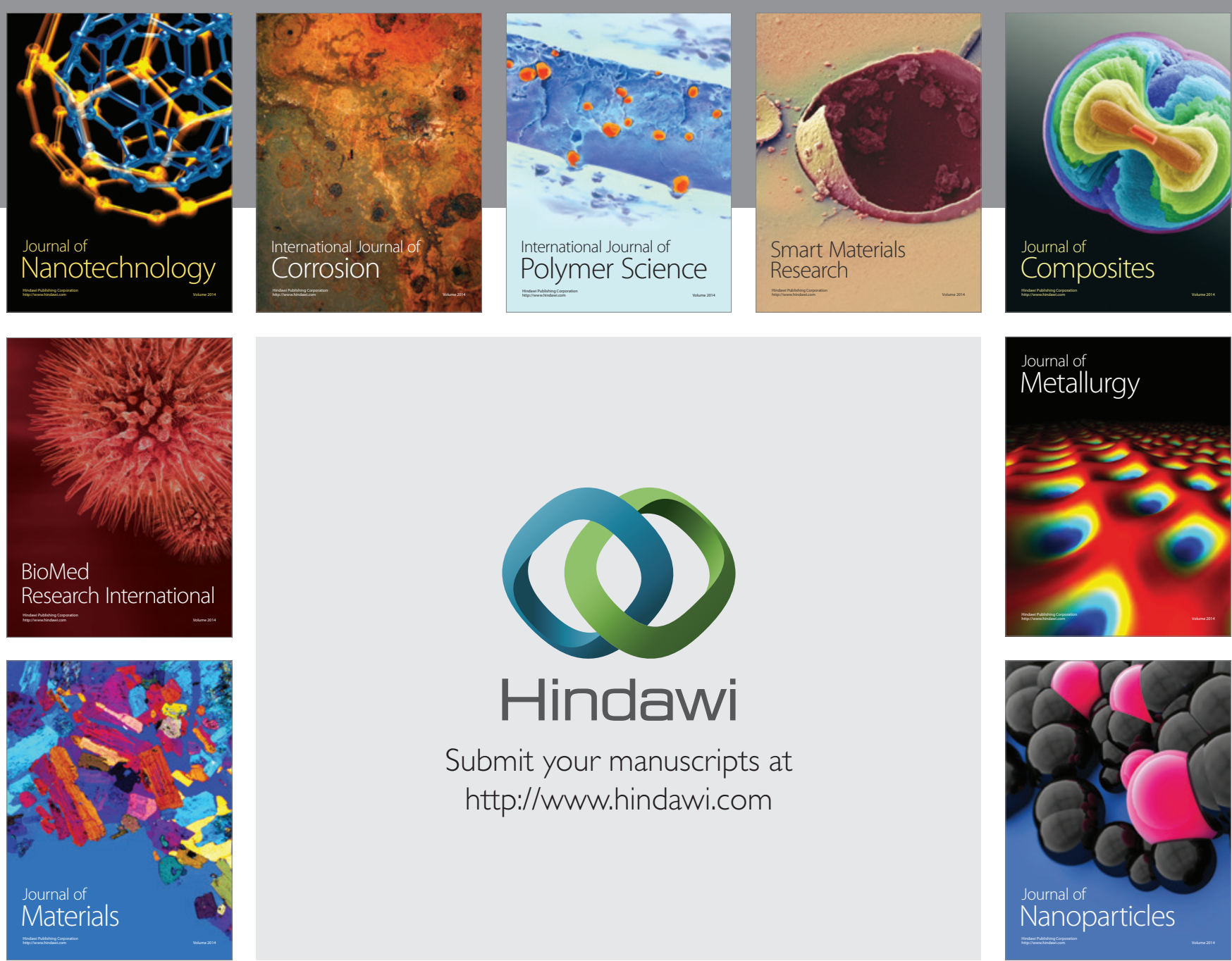

\section{Hindawi}

Submit your manuscripts at

http://www.hindawi.com

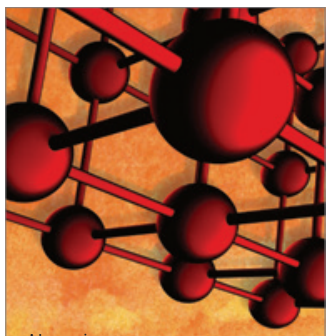

Materials Science and Engineering
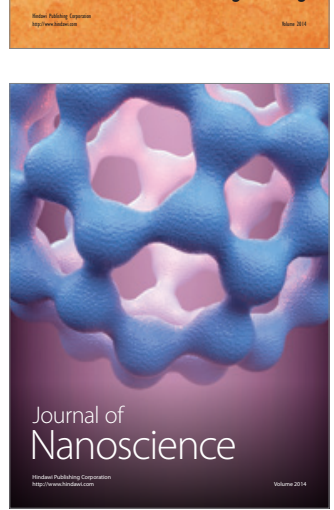
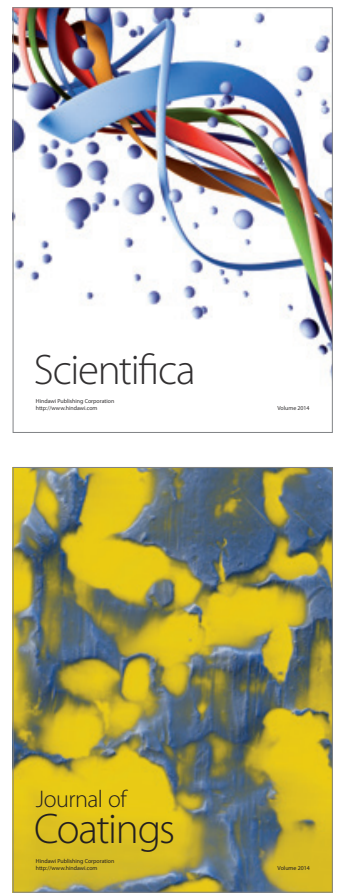
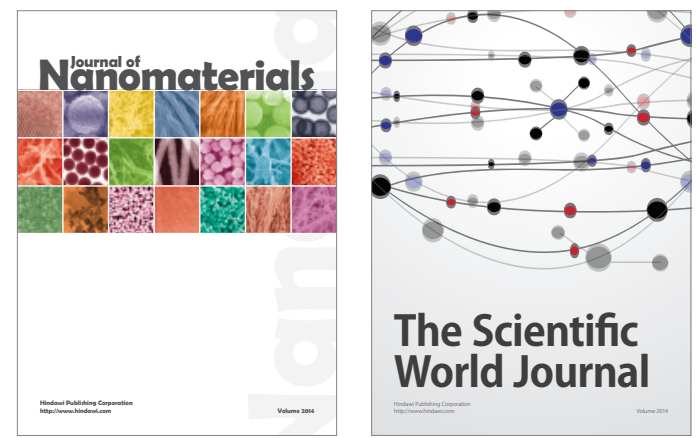

The Scientific World Journal
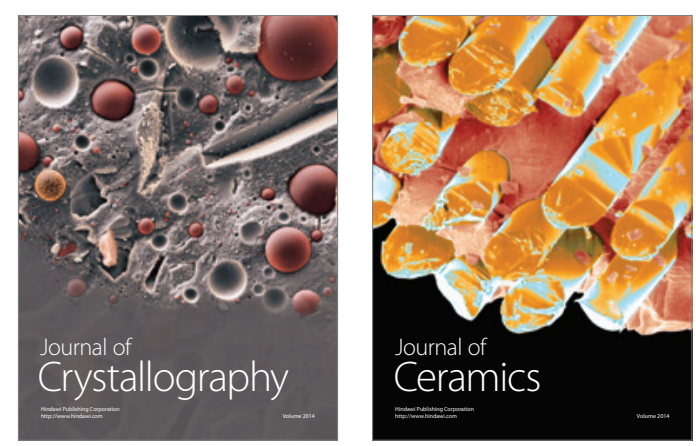
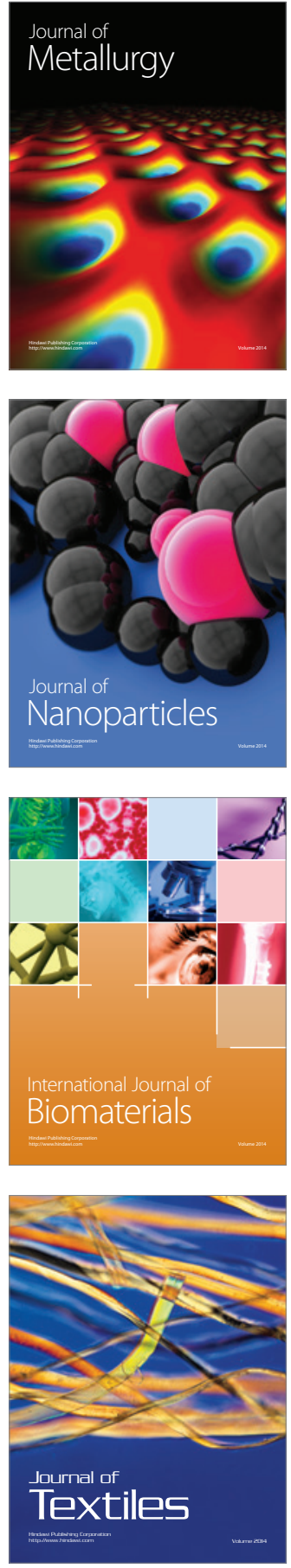